\title{
AS MIL SAÚDES: PARA AQUÉM E ALÉM DA SAÚDE VIGENTE
}

Débora de Moraes Coelho Tania Mara Galli Fonseca Universidade Federal do Rio Grande do Sul, Porto Alegre, Brasil

RESUMO: Este artigo procura problematizar o caráter das estratégias da produção capitalista, no que diz respeito às práticas de saúde dominantes. No contemporâneo encontramos um controle subjetivo, freqüentemente produzido pela mass-mídia, exercido sobre os corpos para que estes se adaptem aos padrões da saúde vigente. Frente a esse cenário, torna-se necessário resistir e criar. A criação de si diz respeito à liberdade de viver a saúde singularmente, experimentando-a de mil modos.

PALAVRAS-CHAVES: Biopoder; saúde; resistência.

\section{THE THOUSAND HEALTHS: GOING MUCH FURTHER THE PRESENT HEALTH}

ABSTRACT: This article aims to question the character of capitalist production strategies concerning dominant practices in health care. In contemporary society, we find subjective control, frequently produced by the mass media, being exercised on bodies so that these may adapt to current health care standards. In face of this, it becomes necessary to resist and to create. The creation of one's self concerns the freedom of living health in a singular way experimenting it in a thousand different ways.

KEYWORDS: Biopower; health; resistence.

Nunca se falou tanto da Vida. Palavra que tem despertado o interesse de quase todos os domínios do conhecimento humano. Passando pela mídia, marketing empresarial, discursos de espiritualidade e campanhas políticas. Tudo em prol da vida: tudo para preservá-la... O discurso atual associou a clássica idéia biológica do sobreviver, aos desejos de viver melhor. Ou, como diriam os slogans publicitários, "viver melhor, viver com qualidade" e, então, a vida passou a significar o nosso maior investimento, seja de tempo, de dinheiro ou de pré-ocupação.

Esta visão maciça de enxergar o viver acaba por extirpar algumas nuances fundamentais da existência humana. Principalmente no que diz respeito às dores e aos desprazeres. Percebe-se que tudo aquilo que se relaciona com o sofrimento deve ser rapidamente tratado, afastado ou resolvido. Sofrer transforma-se em avesso do viver, o que, sem dúvida, limita a visão trágica da vida, onde somos constantemente desafiados a ver a existência com todas as suas facetas. Mas, afinal, de que vida se fala?

$\mathrm{Na}$ atualidade, o conceito de vida transformou-se, ganhando correlação com inteligência, bem estar, saúde e afeto... O que significa dizer que dimensionamos a saúde em $u m$ certo estilo de vida. Trata-se, portanto, de um poder que rege e regulamenta a existência. Controlam-se as diferentes formas de vida e formas do viver, homogeneizando-as em padrões subjetivos e estéticos ao sabor do Capital.

Para que o nosso tema possa ganhar profundidade, somos forçados a pensar na relação que tecemos entre controle e desejo, política e subjetividade, o "eu" e o coletivo. Ou seja, problematizar o caráter das estratégias de produção capitalista torna-se uma necessidade para enfrentar o tempo em que habitamos.

Contaremos com a ajuda de Foucault (2002) que elaborou o conceito de Biopoder na década de setenta. Em sua versão "clássica, poderemos compreendê-lo como um poder exercido sobre a Vida, mais propriamente sobre um corpo individual e coletivo através de tecnologias disciplinares e biopolíticas.

A noção de poder aqui trabalhada, será pensada dentro de uma relação entre forças (toda e qualquer), como uma ação exercida sobre outra ação. Na modernidade, esse poder era usado para gerir a vida sobre os corpos da população e espécie. Ao gosto do tema "ordem e progresso", aplicava-se a vigilância e o treinamento nos estudos sobre os fenômenos vitais do coletivo: nascimentos, mortalidades, nível de vida, longevidade, saúde - principalmente as epidemias. Tudo matematicamente transformado em taxas para melhor "administrar os dados" e promover, através de políticas higienistas, uma vida mais "sadia" para o povo. A era de um biopoder traduz-se no crescimento destes mecanismos reguladores da população global.

Nos dias de hoje, o biopoder passa por um mecanismo de docilizar e controlar os corpos para que se adaptem aos padrões e respectivos produtos de saúde vendidos no atacado e no varejo. O interesse é focado no sujeito, o que nos fala de um investimento do poder sobre a vida, tornando, dessa forma, o poder, biopolítico. Tanto que 
os cuidados com a saúde andam assumindo um lugar cada vez mais pessoal e íntimo, distanciando-se de uma convivência mais coletiva e política.

O que relaciona a nossa passagem pelo estágio neoliberal do capitalismo. Para tanto, se faz necessária a compreensão do que Guattari (1996) chamou de CMI ou Capitalismo Mundial Integrado, ampliando a produção de poder para o terreno subjetivo. A melodia do rap "Tá dominado, tá tudo dominado" parece expressar bem esse momento de supremacia do império norte-americano, em que há todo um "trabalho" de colonização de todos os espaços planetários, homogeneizando as diferenças culturais, políticas e ancestrais dos povos, principalmente daqueles mais empobrecidos ou em desenvolvimento.

Tal configuração do cenário nos aponta que estamos em contato com um poder fluido, de curto prazo, contínuo e ilimitado. Perde-se o centro de referência do poder que se torna presente em todo o sistema e não em um rosto, encarnado em uma pessoa ou localizável em instituições como família, a escola, o hospital, etc. Isto significa dizer que o poder ganha a forma de uma onda que emite incontáveis modulações, tal formação torna-se imaterial e procura seus alvos na inteligência, no inconsciente, no trabalho intelectual. Ainda mais com os efeitos da comunicação instantânea, em suas redes de mass-mídia e virtualizações computadorizadas. É desta maneira que os antigos muros que delimitavam os espaços de dentro e de fora tornam-se fluídos e altamente móveis, fazendo com que o poder afete de forma difusa o corpo social.

Sendo assim, somos tentados a trazer o auxílio de pensadores como Negri e Hardt (2000) para reforçar este ponto de vista e sua incisiva marca subjetivante. O que chama atenção nas idéias destes autores, é que passamos por um período inédito na história, no sentido de que o capital conseguiu alcançar o que havia de mais intenso e íntimo no homem, a saber seu inconsciente, seus desejos, seu potencial de criação. Hoje somos sutilmente envolvidos por uma rede que controla nossa forma de viver, trabalhar, pensar, amar. A perspectiva chegou num tal ponto refinado que já não sabemos se realmente queremos algo ou se somos impelidos a querê-lo.

Traduz-se, aí, uma captura da subjetividade dentro dos sistemas de códigos próprios ao modo de produção capitalísticos. A proposta de docilização dos corpos encontra o seu ápice de sutileza, produz controle contínuo em meios abertos e oferece visibilidade permanente. Eis o grande modo que nos produz na atualidade e frente ao qual desejamos criar resistência.

\section{Biopolíticas da saúde}

É claro que a preocupação em fazer vigorar a norma e o normal aos comportamentos humanos não é recente.
Na história da Saúde, além das preocupações estatais com o corpo salutar e útil à produção, tivemos dois importantes dispositivos de poder interessados em intervir neste mesmo tema: a Religião e a Ciência. Estes definiram e organizaram as regras e uma série de procedimentos em busca de soluções eficientes às doenças através da cura do corpo que sofre e do alívio da alma que peca. Só que nos dias atuais há um certo jogo perverso, no qual contamos com o poder de persuasão das idéias de prazer e de felicidade que são constantemente recodificadas pelo mercado e pela mídia.

A saúde, assim tratada, vira objeto de consumo. Isto ocorre porque ao estarmos imersos numa cultura consumista, as maneiras de se "ter" saúde tornam-se produtos de vendas. Como se o desejo desejasse obrigatoriamente, uma mercadoria. Assim, frente às exigências de possuir uma saúde que corresponda ao modelo padrão, há um esquecimento de como funciona o corpo singular, fazendo com que o sujeito grude no imaginário corporal dominante.

O "culto" exercido, geralmente, é desenvolvido a partir de uma saúde que não é sua, mas de um "outro", montado e construído como uma miragem a ser seguida e idealizada. Esse emblema acaba gerando um desrespeito à vida, seja na arriscada busca por uma saúde ideal, ou pela brutalidade dos mecanismos utilizados. Como bem observou Denise Sant'Anna, em seu livro Corpos de passagem (2001, p. 61): “Shoppings, parques, resorts, megaparaísos do consumo onde é preciso coragem para comprar menos e mais do que coragem para frear o desejo de consumir. Principalmente quando os apelos são claramente dirigidos à beleza e à saúde."

Um dos efeitos produzidos é todo um alarde midiático e cientificista de uma "Gorda Saúde Dominante". Esta expressão deleuziana trata das práticas dominantes ou maiores de se pensar a Saúde. Principalmente na questão de que tudo que surge como novidade (qualquer alimento, elemento) pode ser engolido, mas nada é digerido, processado.

Neste cenário, o corpo é o principal alvo de preocupações. Funciona como uma marca identitária, tendendo a expressar um único $\mathrm{eu}$, como se este fosse exclusivo a cada um e sem ligação nenhuma com o campo social. Pode-se batizá-lo de "corpo fechado", já que tende a minorizar a força intensiva das experiências que a relação com o mundo produz. Mas, como diria Arnaldo Antunes, "o corpo tem alguém como recheio."

Aqui, abriremos um breve parêntese para entender o que seria esse recheio, essa marca identitária, esta forma de organização de si mesmo que é vivida como interioridade narcísica ou como controle de si/culto de si. Jurandir Freire Costa (2004, p. 190) reforça nossa discussão ao dizer que: 
... o cuidado de si, que antes era voltado para o desenvolvimento da alma, dos sentimentos ou qualidades morais, dirige-se agora para a longevidade, a saúde, a beleza e a boa forma. O que nos faz entender que ser jovem, saudável, longevo e atento à forma física tornou-se regra científica que aprova ou condena outras aspirações à felicidade.

A ditadura da indústria da forma é tão perspicaz que parece lutar em prol de uma (pretensa) saúde, sendo, inclusive, denominada desta forma. Então, como produzir uma prática de saúde que não beire o excesso, redução ou extremo? Como exercitar uma saúde que contenha em si o cuidado pelo social? Difícil tentativa em tempos em que práticas como o egoísmo, o fechar-se em si e temer o outro são naturalizadas e estimuladas em um mundo que prega $\mathrm{o}$ amar demais a si como lei número um. Muito do que hoje é chamado de amor exclusivo pelo próprio corpo, ao invés de fortalecer as relações de cuidado e afeto por si, tornou-se uma satisfação própria de uma variação sem sentido e sem responsabilidades para com os outros.

Há algum tipo de angústia coletiva pairando no ar, angústia esta que atribui créditos e ideais de salvação aos discursos e procedimentos cientificistas sobre a saúde. Sinal de que o olhar do homem não é mais suficiente para avaliar se um corpo "tem saúde ou não". São os exames médicos, alicerçados por todo um aparato sofisticado da tecnologia, que apontam como está o estado salutar do sujeito. Costa (2004) nos aponta que o espaço do universal, do incontestável, passou a ser ocupado pelo mito cientificista, o qual conquistou o direito intelectual de falar do lugar da Verdade. Agora, o bem ou o bom também passam pela distância ou proximidade da qualidade de vida.

O que mingua aí é o saber sobre o próprio corpo; o que favorece que toda uma rede de especialistas ganhe status de um conhecimento sério e correto (via ciência) sobre "as regras de funcionamento corporal saudável". Estas percepções nos dão margem para que possamos pensar na construção contemporânea de um corpo guiado pelos encantos midiáticos e comerciais, adestrando o sujeito a como construir para si um corpo saudável.

Esta seria o que anteriormente chamamos de Gorda Saúde Dominante. Uma saúde de ferro que toma nossos corpos. Ela funciona "bem demais", consome tudo que encontra pela frente, mas também vomita tudo, no seu apetite voraz não encontra tempo para digerir aquilo que devora. Das possíveis variações que encontra, só deixa passar aquelas que não vão abalar sua forma identitária. Isto porque a saúde gorda, além de viscosa, gruda em nossa pele. Ajuda a manter um certo controle sobre o devir da vida. Idéia de estabilidade, afinal de contas, estas garantias sempre encantam o nosso desamparo inicial. Esta é uma das políticas em relação ao mundo. A que luta, com lemas e slogans, para permanecer protegida em seu pretenso molde. Saúde, sob este ponto de vista, serve como parâmetro de equilíbrio entre seus elementos para melhor funcionar. Controlando os excessos, desordens e desequilíbrios, a máquina pode funcionar bem e, com sorte, escapar dos caminhos que poderão degenerar em patologias físicas ou psíquicas.

\section{As Mil Saúdes}

A pergunta que continua a nos mover é como poderemos contrapor o poder sobre a vida com o poder $d a$ vida. Fazendo vingar nossa vontade atual de possibilitar, um outro jeito de viver no mesmo mundo. Percorrendo uma geografia constantemente reinventada, supomos que nossa tarefa é enxergar a vida e a saúde nas coisas. Esta seria a biopotência, uma das facetas da biopolítica, que surgiria com a força do poder de construção ontológica, reafirmando que há uma variação universal, um perpétuo se distinguir.

Deleuze (1997) nos explicita que ao Biopoder (poder sobre a vida) deveria responder o poder da vida (Biopotência), vejamos, mais atentamente, como esse processo se daria. Lembramos de uma situação comum nos dias de hoje: não haveria uma certa competição em conversas cotidianas toda a vez que o tópico "aparência física" surge? Quem come menos gordura? Quem ingere vegetais sem agrotóxicos e farinhas integrais? Quem deixou de fumar há mais tempo? Tais perguntas trazem uma sensação de desconforto, porque servem para medir quem possui uma saúde mais ou menos problemática. Essa avaliação denuncia que existe a afirmação de um "tipo" de qualidade de vida que carrega em si um discurso que não suporta os meios tons, os meios equilíbrios, os meios acertos, transformando suas advertências em dogmas incondicionais.

Resistir a toda uma série de regras externas que ditam quais caminhos devemos percorrer para ter "mais" saúde, seria, portanto, acionar a potência política da vida que nos fala Deleuze (1997). Ao dar passagem a tal potência poderíamos reinventar novos eixos de enunciação a partir de cada engendramento de forças que nos fosse possível agenciar.

O que desejamos ressaltar é que do lado do poder há sempre resistência. Foucault (2002) já nos alertava para o seguinte paradoxo: toda a vez que o poder investe a vida, a resistência se entranha nesta mesma vida que o poder investe. A biopotência assim compreendida quer ver a vida no interior de um complexo agenciamento de transformação. E isto significa, muitas vezes, atrever-se a desejar de outro modo, percorrendo outras escolhas que podem manifestar-se, inclusive, em outro ritmo de mover nossos corpos no cenário que até então estamos desenvolvendo. Este resistir a não seguir todos os ritmos impostos por esta biopolítica, refere-se a não submeter 
mais o corpo a um funcionamento que não lhe é próprio e, portanto, singular.

Segundo Lapoujade (2002, p. 89), o reencontro com a resistência que o corpo manifesta frente aos mecanismos de adestramentos e disciplinas, pode ser expresso na frase: "eu não agüento mais". Tal enunciado não é, portanto, "o signo de uma fraqueza da potência, mas exprime, ao contrário, a potência de resistir do corpo." a qual faz surgir um profundo fortalecimento na construção de um limite subjetivo.

Tal idéia nos faz falar não mais de uma gorda saúde dominante, mas sim de uma frágil saúde, ainda em vias de se tornar forte, a partir dos espaços que pode ir vivendo enquanto executa sua trajetória. A concepção nietzschiana de "corpo" (1986) como algo que não diz eu, mas faz o eu, nos é bem vinda. Porque o corpo pode ser entendido para além da sua visão de organismo, com todo seu conjunto de carne, ossos, órgãos e tecidos; ou de sua imagem mais ou menos estável que enxergamos refletida no espelho. Para além dos parâmetros médicos, psicológicos e mecânicos, um corpo expressa-se no combate incansável entre vida e morte, brincando com os limites entre o que há de moribundo e de embrionário em cada ser vivo.

Esse é o esforço que fazemos aqui: reencontrar as forças do corpo, enxergá-lo como um campo de multiplicidades produtivas, para assim não sucumbir à tentação de fechá-lo, ao vê-lo como uma fronteira a ser vencida, explorada e controlada. Muito mais ao gosto do pensamento deleuziano, definiríamos um corpo através de sua ligação entre as forças dominadas/reativas e as forças dominantes/ativas. Um corpo assim compreendido é pura relação, movimentando-se no encontro com a alteridade.

É esta forma de viver o corpo que encarna uma saúde que é seletiva e procura em seu processo vital as possíveis passagens de transfiguração. O que ressalta a afirmação de um processo singular de saúde, em que se reconhece de quê o corpo precisa e não o quê deve precisar. Aprimorando a técnica de escutar o próprio corpo, entramos em contato com suas vontades, seus ritmos e seus apetites, exercitando, para tal, uma desaceleração temporal, advinda deste tempo da delicadeza.

Para encarnar tal saúde é preciso uma certa reserva, um certo silêncio, um certo vazio, para apreender de modo intensivo esse excesso de mundo. A criação de vacúolos de não comunicação serve como ponte de passagem para que algo possa acontecer. Se com o biopoder encorporamos um tempo veloz demais, aqui a proposta é outra: podemos nos tornar lentos, silenciosos, leves... Acompanho o pensamento deleuziano quando nos diz que combateria pelo frágil desabrochar da vida e não cederia jamais... Por um sujeito que pudesse gozar de:

“... uma frágil saúde irresistível, que provém do fato de ter visto e ouvido coisas demasiado grandes para ele, fortes demais, irrespiráveis, cuja passagem o esgota, dandolhe contudo devires que uma gorda saúde dominante tornaria impossíveis" (Deleuze, 1997, p. 14).

Protestamos por essa lógica: a da permeabilidade ao sutil. Para que tal operação seja feita será preciso produzir em nossas peles uma certa porosidade aos excessos do mundo. Necessitamos do convívio com a precariedade, pois é ela que favorece as entradas, ou as intrusões desta vida, sem as certezas inteiriças e acabadas. É neste movimento que surge uma aptidão em estar, simultaneamente, aberto às afecções e distante de uma força violenta que nos destrua.

Trabalhar com este princípio de saúde passa por libertar a vida lá onde ela está submetida a uma forma majoritária e determinista. Se concordarmos que viver a saúde é também viver um processo de saúde-adoecimento, é porque sentimos que os estados precários e imperfeitos das pessoas também fazem parte da saúde. Saúde não é a repetição sem graça do viver, mas o poder circular pela amplitude de estados e afetos e, conseqüentemente, de relações que conseguimos fazer, nas nossas andanças pela vida. Como bem nos lembra Dejours (1986):

O estado de saúde não é certamente um estado de calma, de ausência de movimento, de conforto, de bem estar e de ociosidade. É algo que muda constantemente... A saúde é quando ter esperança é permitido. $O$ que faz as pessoas viverem é antes de tudo seu desejo.

Eis nossa concepção trágica do mal-estar. Isto porque o processo de criação não passa só por momentos de prazer; ele encarna a dor e o sofrimento também. Podemos alargar tal conceito e pensar que ele vai além do que anunciar o sofrimento. O mal-estar é um sinalizador de um processo de invenção, de novidade, está se dando. É inerente ao processo de criação de novas referências do mundo, sendo expresso sob a forma de desassossego, desestabilização, estranhamento, sentidos em nossas existências individuais e coletivas. Portanto, exige a constituição de outros modos de subjetivação. Afinal, não seria do fundo de nossa impotência que extraímos uma potência superior? O ensinamento nietzschiano não seria que o mais assustador pode trazer em si o mais promissor?

Viver, poderia ser, até o ultimo pensamento e o mais intenso olhar, trans-formar-se, ultrapassando as formas em favor de outras forças, defasando-nos, como bem nos ensinou Simondon (2003). Para tal desdobramento será preciso uma certa tranqüilidade nesta queda da permanência. $\mathrm{O}$ que demonstra que queremos a transição e $o$ processo, por mais que esta lucidez nos perturbe.

Isto nos faz buscar horizontes mais amplos... Levandonos a perceber que quando os corpos encarnam uma outra saúde - a saúde que seu corpo deseja criar, aquele corpo exaltado do qual nos fala Nietzsche (1986) se liberta de 
séculos de repressão, maltratos, auto-punições e violência. Quase como se arrastássemos a cadeira para fora da zona de sombra e sentássemos um pouco ao sol. A beleza é reencontrada, a vida permite que o corpo sinta a alegria e o prazer com toda sua extensão, sem culpa. Ética da afirmação.

Para poder experimentar a variação de saúdes pensamos em apresentar o conceito de corpo paradoxal que Gil (2002) nos traz. Este seria o corpo virtual ou latente em todos os tipos de corpos empíricos que nos formam e nos habitam. Corpos múltiplos, construídos de acordo com as mais diferentes práticas e saberes. Pena que em todos esses séculos de primazia da Razão, desaprendemos a nos comunicar, com mais serenidade, com nosso corpo intensivo. Foi decalcado em nossa pele um corpo orgânico com seus contornos bem definidos. E ficamos na plena posse de um corpo identitário e enclausurado em si mesmo. Só que não percebemos que ao mesmo tempo em que nos agarrávamos em uma forma, íamos perdendo a força vital do corpo. De acordo com tal potência descobrimos que nosso corpo, é na verdade, segundo Gil: "feito para desaparecer. Quando se tem um corpo próprio, localizado no espaço, o corpo empírico da Medicina, dos esportes, das top-models... entramos na desgraça dos corpos" (p. 146).

O lugar em que acontece tal "desaparecimento" pode ser compreendido como um espaço de vertigem, mas também um momento de repouso, este presente trêmulo e delicado pode trazer um efeito transformador. Estar nesse local pode parecer incerto e inseguro, mas é também um grande alívio, funcionando como uma lenta reconcialização com o processo de viver. A tática está em nos familiarizarmos com as linhas que teimam em nos desalojar do confortável território. Elas querem fazer fugir, mas não como um distanciamento de presente, mas como uma pronta atenção a este. Principalmente aos pontos de subjetivação que se totalizaram, engessando expressões possíveis. Saber que as linhas de fuga vão nos relançar no processo, é entender sua relação íntima com o imprevisível. Aqui fugir aproxima-se de criar, experimentando as novidades (e os perigos) podemos extrair a vida que tais linhas carregam. Tal abertura e flexibilidade que exigimos dos nossos corpos trazem a força a nossa empreitada, estas forças não surgiram da resistência aos medos, mas sim do conhecimento que conseguimos ter deles. É conhecendo os passados que se conservam em nós, que poderemos fazer pressão sobre nosso presente.

Com a saúde acontece um movimento semelhante. Não há uma saúde, com trajeto linear. Ela também é feita para desaparecer, dando lugar a outras expressões de produção de saúde que se encontram virtualmente compostas num reservatório de possíveis. Eis o processo se dando, eis uma saúde paradoxal se forjando. Eis a biopotência encontrando maneiras de resistir a saúde dominante, abrindo um novo campo de possíveis para que possamos habitá-lo.

\section{Referências}

Costa, J. F. (2004). O vestígio e a aura: Corpo e consumismo na moral do espetáculo. Rio de Janeiro, RJ: Garamond.

Deleuze, G. (1997). Clínica e crítica. São Paulo, SP: Ed. 34.

Dejours, C. (1986, abr./maio/jun.). Por um novo conceito de saúde. Revista Brasileira de saúde Ocupacional, 54(14), 7-11.

Gil, J. (2002). O corpo paradoxal. In D. Lins \& S. Gadelha (Eds.), Nietzsche e Deleuze: Que pode o corpo? (pp. 131-147). Fortaleza, CE: Relume Dumará.

Guattari, F., \& S. Rolnik (1996). Cartografias do desejo. São Paulo, SP: Vozes, 1996.

Foucault, M. (2002). História da sexualidade: Vol. 3. O cuidado de si. Rio de Janeiro, RJ: Graal.

Lapoujade, D. (2002). O corpo que não agüenta mais. In D. Lins \& S. Gadelha (Eds.), Nietzsche e Deleuze: Que pode o corpo? (pp. 81-89). Fortaleza, CE: Relume Dumará.

Negri, A., \& Hardt, M. (2000, Mars). La production biopolitique. Majeure, Paris, 1.

Nietzsche, F. (1986). Assim falava Zaratustra: Obras escolhidas. Lisboa, Portugal: Relógio D’Água.

Sant'Anna, D. (2001). Corpos de passagem: Ensaios sobre a subjetividade contemporânea. São Paulo, SP: Estação Liberdade.

Simondon, G. (2003) A gênese do indivíduo. In P. Pelbart \& R. Costa (Eds.), O reencantamento do concreto. São Paulo, SP: Hucitec.

Débora de Moraes Coelho é Psicóloga, Mestre pelo Programa de Pós Graduação em Psicologia Social e Institucional na Universidade Federal do Rio Grande do Sul (UFRGS), participa do grupo de pesquisas "Modos de trabalhar, modos de subjetivar" na UFRGS.

debora@intersecpsico.com.br

Tania Mara Galli Fonseca é Psicóloga, professora do Programa de Pós Graduação em Psicologia Social e Institucional na UFRGS, coordena o grupo de pesquisas "Modos de trabalhar, modos de subjetivar" na UFRGS. Endereço para correspondência: Avenida

Dom Pedro II, 1610, sala 101, Higienópolis, Porto Alegre, RS, 90550 141. Telefone/fax: (51) 3343-0261.

ritornelo@bol.com.br

\section{As Mil Saúdes: para aquém} e além da saúde vigente

Débora de Moraes Coelho e Tania Mara Galli Fonseca

Recebido: 30/03/2006

$1^{\text {a }}$ revisão: 08/09/2006

Aceite final: 26/01/2007 